\title{
GIS-Based Biomass Energy Sustainability Analysis Using Analytical Hierarchy Process: A Case Study in Medellin, Cebu
}

\author{
Wenyville Nabor Galanga,b*, Ian Dominic Tabañagc, Michael Loretero ${ }^{\mathrm{d}}$ \\ ${ }^{a}$ School of Engineering, University of San Carlos, Cebu City, Cebu, Philippines \\ ${ }^{b}$ College of Engineering and Computer Studies, Holy Name University, Tagbilaran City, Bohol, Philippines \\ c Department of Chemical Engineering, University of San Carlos, Cebu City, Cebu, Philippines \\ d Department of Mechanical and Manufacturing Engineering, University of San Carlos, Cebu City, Cebu, Philippines
}

\begin{abstract}
The increasing demand for energy accounts for an alternative energy source. The search for biomass being abundant in an agricultural country is a suitable option to power a community. This paper used Analytical Hierarchy Process (AHP), which includes the organized hierarchy of various selection criteria, the assessment of the relative value of criteria, the comparison and an aggregate rating of the alternatives for each criterion. Specifically, the methodology used was the combination of multi-criteria and weighted-overlay analysis in a Geographical Information System (GIS) environment to provide a spatial overview of the sustainable location for sugarcane residues production in Medellin, Cebu. The study was able to identify Caputatan Sur and Canhabagat as sustainable locations for sugarcane residue production with respect to topography, cultivation area and accessibility. These locations represent $26 \%$ of the total cultivation area and average sugarcane production of the locality. The result of this study is an initial step in the support for the utilization of sugarcane residues to answer energy demand in remote areas and further promote the use of indigenous resources for energy generation.
\end{abstract}

Keywords: AHP, Biomass, GIS, MCA, Sustainability, Waste to Energy

Article History: Received: $1^{\text {st }}$ October 2020; Revised: $7^{\text {th }}$ February 2021; Accepted: 10 ${ }^{\text {th }}$ March 2021; Available online: $15^{\text {th }}$ March 2021 How to Cite This Article: Galang, W.N., Tabañag, I.D., and Loretero, M. (2021) GIS-based Biomass Energy Sustainability Analysis Using Analytical Hierarchy Process: A Case Study in Medellin, Cebu. Int. Journal of Renewable Energy Development, 10(3),551-561

https://doi.org/10.14710/ijred.2021.33260

\section{Introduction}

In recent years, many countries have made efforts to become less dependent on fossil energy supply by means of promoting renewable energy production. These efforts lead to an increased attention for the clean, green, and safe characteristics of renewable energy (RE). RE pushes the energy structure towards a balanced degree by delivering a sustainable solution to energy production (Souza et al., 2015; Vera and Langlois, 2007), and adding to the long-term reduction of the greenhouse effect, and plays a key role in the overall sustainable growth policy (Dincer, 2000). The importance of renewable energy extends from energy security to economic and local development.

Biomass opportunities for bioenergy have the ability to shift the world toward a more sustainable future as a clean energy source (Souza et al., 2015). Biomass is a form of energy extracted from plant biomass, as well as residues and wastes derived from plants. Solar energy and $\mathrm{CO}_{2}$ are converted into biomass by photosynthesis (Souza et al., 2015). The utilization of bioenergy returns $\mathrm{CO}_{2}$ to the atmosphere in a sustainable cycle. Biomass conversion processes yield energy in the form of electricity, fuel and heat.

One of biomass energy sources includes agricultural crops and residues such as from sugarcane (Boyle, 1996; Milbrandt and Overend, 2008; Samson et al., 2001). Cane trash and bagasse are two varieties of residues of biomass extracted from sugar cane. Cane trash is the residual field left after the cane stalk has been harvested, and bagasse is the fibrous residue left after the cane has been milled. The diversity, maturity of sugarcane, methods of harvesting and efficiency of sugar processing have an important effect on bagasse composition (Boyle, 1996). Bagasse is also emerging as an attractive feedstock for bioethanol production (Milbrandt and Overend, 2008; Samson et al., 2001).

Biomass for energy generation can help improve energy security. The way for securing energy in the developing countries means gearing toward efficient utilization of biomass resources for bioenergy. Depending on the region, biomass products such as those derived from crop residues can be used in small factories, burned as cooking fuel in homes, disposed of or left on the field for soil protection. Sugarcane is the top agricultural crop grown in the Philippines, with paddy rice, coconut, corn,

\footnotetext{
*Corresponding author: naborgalang@gmail.com
} 
banana and plantain rounding out the top five (FAO, 2017; PSA, 2018). In contrast to bagasse used in cofiring for power generation, sugar cane waste is mostly left in fields and burnt in preparation for the next growing period (Go \& Conag, 2019). Burning is the most frequent remedy where agricultural residues are excessive and prevent the next growth of crops. The act of burning lowers working time and costs, but impacts neighboring communities, land resources and the atmosphere adversely (Morato et al., 2019). In the Philippines, findings on the recovery and use of sugarcane trash have been limited, considering the fact that it is the top-produced crop (Go \&Conag, 2019). These crop residues are currently underutilized, limiting their ability as renewable energy sources to the maximum extent possible.

Biomass for electricity generation plays an important part in the energy mix in a developing country like the Philippines. Bioenergy will help increase energy efficiency for the $15 \%$ of the country's population who do not have access to electricity. It has the potential to bring rural areas out of poverty, paving the way for a more prosperous and inclusive future. Access to dependable and affordable energy is critical for long-term economic and environmental sustainability. Biomass in the form of sugarcane is the most abundant crop produced in the Philippines, with the central islands (Visayas region of the country) accounting for approximately $68 \%$ of its production (Go and Conag, 2019). If all the sugarcane leaves/straws produced in the Philippines were harvested, the average amounts to $17.48 \pm 0.82 \mathrm{MJ} / \mathrm{kg}$, attributing to $59.9 \pm 1.3$ PJ of energy annually, or 5.9 TW-h of electricity, assuming a normal power plant efficiency of $36 \%$ (Go and Conag, 2019). Based on the annual production of sugarcane trash $(2.3 \pm 0.7 \mathrm{Mt})$ in the Visayas Region, 40.2 $\pm 1.1 \mathrm{PJ} /$ year could be retrieved, generating up to $4.0 \mathrm{TW}$ $\mathrm{h}$ of electricity. This could account for up to $30.8 \%$ of the Visayas grid's overall electricity production (13 TW-h) in 2016 (Electric Power Industry Management Bureau (EPIMB) \& Department of Energy (DOE), 2017). The Visayas region produces $57 \%$ of the country's sugarcane. The Visayas islands, which have over 28 thousand sugarcane fields, should be at the forefront of using sugarcane trash as a bioenergy source (Go and Conag, 2019).

The abundance of biomass in the surrounding makes it a low cost option for alternative power sources. An analysis of potential sources is needed to assess the abundance and volume of potential energy that can be used as an alternate power source. Resource assessment accounts the bioenergy potential of a residue in a specific area. In the same manner, resource assessment leads to identifying areas with high energy potential and guides the decision-makers in determining suitable areas for power plant development. Initial assessment of biomass energy potential entails identifying potential site, sustainability, production and consumption.

Several studies have attempted to quantify the amount of biomass that is currently usable in the Philippines and around the world (Avcioğlu et al., 2019; Cadalin et al., 2015; Novero et al., 2019; Sevilla et al., 2015a; Sevilla et al., 2015b). All these studies show the amount of agricultural crops available for bioenergy. In particular, future agricultural production and demand assumptions have a significant effect on the results. However, in the
Visayas region, particularly in the municipality of Medellin, there is uncertainty on the amounts of available waste and residue resources that could be tapped into for renewable sources of energy. Another source of confusion is the strictness of the description and implementation of standards for sustainable biomass production. Basically, the aim of this study is to determine the sustainable area of biomass residue supply for energy generation. This study explores an initial evaluation of sugar cane waste as a potential resource for the generation of bioenergy while estimating its local supply and potential for bioenergy generations as a basis for policy and decision-making with regard to the government's objective to promote the use of indigenous sources for energy use.

Several strategies have been presented in scientific literature aimed at integrating sustainability metrics in bioenergy systems, taking into account policy statements and technology availability, and one of the commonly used techniques is multi-criteria analysis (MCA) (Zopounidis et $a l, 2010)$. MCA is a set of systematic methods aimed at taking into account various criteria in the exploration of choices by individuals and organizations (Belton and Stewart, 2002). It is a tool that involves the strategy used to identify the best solution or scenario within a range of options. MCA is a general term used to characterize any decision where several and contradictory factors have an impact on the decision. Criteria can take the form of attributes or objectives, attributes are traits, quality or efficiency measurements, while objectives are indicators that represent the preferences of decision-makers (Scott et al., 2012). MCA is a broad set of approaches that are regularly used to facilitate decision-making when different requirements and decision-makers are involved. The MCA methods can be defined as discrete and continuous methods. Continuous approaches pursue an optimal alternative among a large number of alternatives by optimizing the utility function. Decision-makers' expectations are included as mathematical objective functions and limitations. On the other hand, discrete methods are based on the choice of the best alternative from a certain number of alternatives. Sustainability evaluations are usually discreet preference issues where there are a variety of options to be compared. The Analytical Hierarchy Process (AHP) is a discreet MCA tool widely used to determine sustainability (Myllyviita et al., 2013).

In the bioenergy area, the subject of sustainability is relevant and is frequently studied through multi-criteria decision-taking in many disciplines. Sustainability is the most common theme for multi-criteria research to discuss the set of sustainability assessment or consideration studies (Scott et al., 2012). The Analytical Hierarchy Process is a common group of optimization techniques in the category of finite choices where group of outranking methods founded on the principle of pairwise comparison. AHP is a measurement technique that makes pairwise analyses of decision factors and ranks alternatives using expert experience. The AHP detects inconsistencies in expert feedback through a consistency check; inconsistent expert input is removed from a decision issue review to ensure the quality of expert expertise (Budak et al., 2019). The AHP allows experts to adjust their assessment through a reaffirmation approach and fine-tune their assessment for impartial decision-making. 
MCA approaches have been applied widely in the energy and bioenergy sectors (Budak et al., 2019; Giri et al., 2016; Kurka, 2013; Myllyviita et al., 2013; Sultana and Kumar, 2012). The methodology includes the analytical hierarchy process (AHP), the preference organization approach for enrichment assessment, and the innovative solution to imprecise assessment and decision-making environments as well as their derivations (Scott et al., 2012). The implementation of the AHP method to assess the production of bioenergy in relation to its regional sustainability has been carried out (Kurka, 2013). Related studies involve an MCA approach including geographic key stakeholders or bioenergy experts working, which makes it possible to take note of the number of standards and benchmarks, as well as a wide range of views, strategies and objectives.

The application of MCA using the AHP approach extends from sustainability to other environmental applications. It includes technique integration in addressing significant problems faced by the groundwater system. The study concentrated on methodological development of identifying potential groundwater recharge sites in Philippines' hydro geographical set up (Sandoval and Tiburan, 2019). It also highlights the use of the Weighted Sum GIS tool as a companion for AHP as it enables creation of potential maps for the study of groundwater recharge. Another research assessed the technologies for transforming biomass to biofuels by various criteria decision-making based on the weight of criteria determined by AHP (Kheybari et al., 2019). The study identified a rigorous framework of standards for the assessment of technologies and the result identified the most significant consideration for the assessment of energy technology generation from biomass. One of the common applications of AHP involves the evaluation of land suitability. AHP is one of the multi-criteria decisionmaking methods widely used in agricultural land use study of suitability (Akinci et al., 2013). AHP is helpful in determining the relative value of the various variables of land suitability for a particular crop, such as sugar cane. The research used the advantage of the AHP method to assess the effect of various variables on the yield of sugar cane growing areas in the Philippines (Alburo et al., 2019).

Achieving renewable bioenergy production is a challenge due to the scope of this field and the multidimensionality of the sustainability objective. One of the benefits of MCA is the possible integration with other systems and technologies to create more versatile mixing approaches relative to separate techniques. Aid can be given by the combination of spatial analysis and MCA. As reported (Malczewski et al., 2015), geographic information systems (GIS) will make it useful for researchers and decision-makers to test and validate spatial relations and the implementation of MCA in a more sophisticated and practical way than would otherwise be necessary to create new options for socio-economic and environmental planning and management. In this context, this study focuses on the best localization of potentially sustainable resources with the merged spatial analysis and AHP to define sugarcane crop residue source in Medellin.

\section{Materials and Methods}

\subsection{Study Area}

The Philippines in particular, along with other developing countries, boast large inventory of unutilized biomass from extensive agricultural activity. Biomass is a low cost and important renewable resource. Estimates on Philippine's collective biomass potential are wide and varied. Sugarcane is the country's most widely grown agricultural crop, and the residues left behind during harvesting can be used to generate electricity (Go and Conag, 2019).

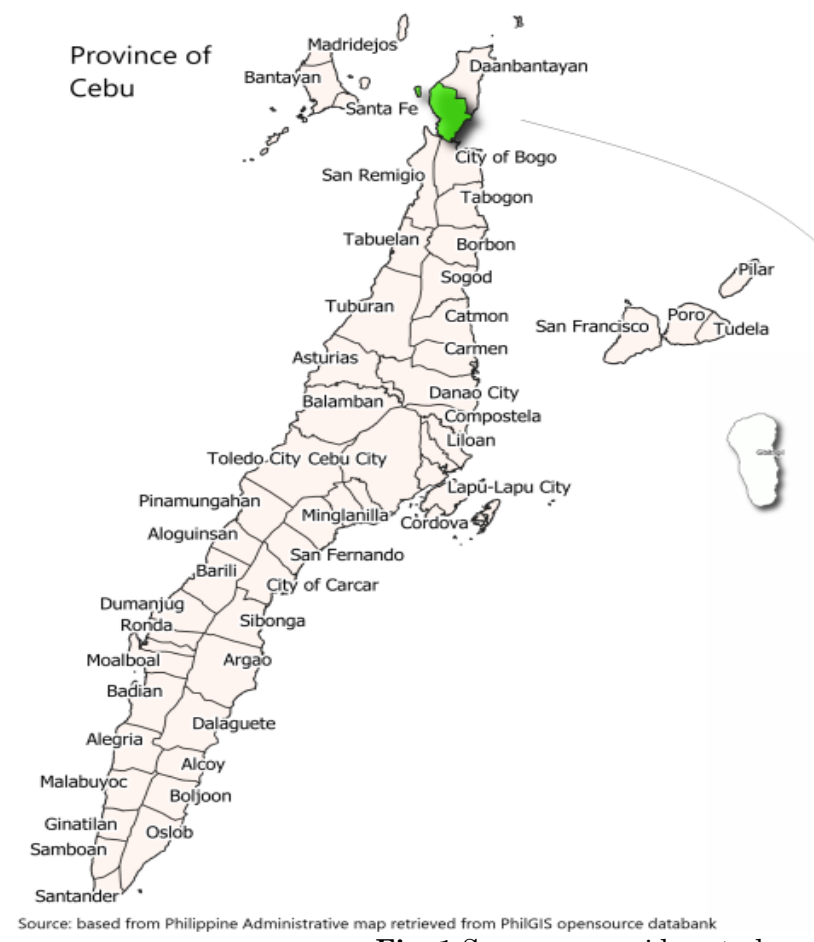

Fig. 1 Sugarcane residue study area

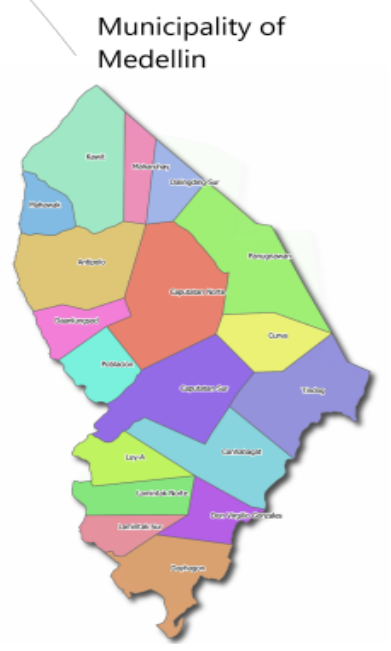




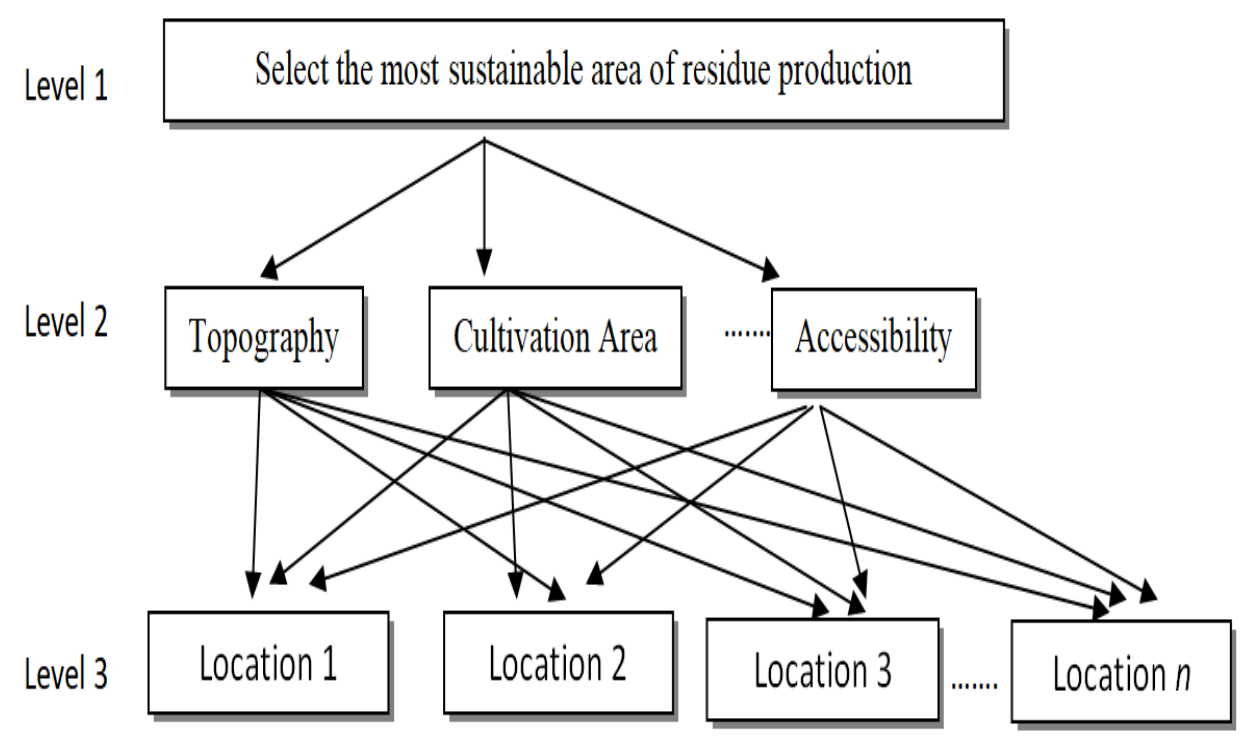

Fig. 2 AHP Decision Hierarchy, Source: adapted based from Saaty, (1987)

The study area is a municipality abundant in sugarcane production as shown in Fig. 1. It is the second class municipality in the province of Cebu. Medellin is one of nine municipalities that make up the province's fourth district. Medellin is 120 kilometres north of Cebu City and is surrounded on three sides by the towns of Daanbantayan, San Remigio, and Bogo. In 2018, the Philippines produced about 24.7 million metric tons of sugarcane cultivated across 437,000 hectares of land area (PSA, 2018). The municipality is part of the Bogo-Medellin mill district in the province of Cebu along with Bogo, Borbon, San Remegio, Daanbantayan and Tabogon. Cebu is part of the Central Visayas region with a $9.88 \%$ sugarcane crop percentage distribution of production. The municipality is abundant in sugarcane whereas the mill district has a total sugarcane area of 7,900 hectares with a total sugar output of 27,297 tons, accounting for 1.12 percent of national production in crop year 2013-14 (Sugar Regulatory Administration, 2015).

\subsection{Analytical Hierarchy Process (AHP)}

The Analytical Hierarchy Process (AHP), a hierarchical approach for arranging and evaluating dynamic decision parameters (Saaty, 1990), is considered to be the most effective methodology for achieving a weighting scheme for prioritizing significant variables in the evaluation perspective (Ding, 2008). The effectiveness of AHP in designing a suitable sustainability analysis weighting scheme has been shown (Kamaruzzaman et al., 2016; Wong \& Li, 2008; Xiong et al., 2007; Zheng et al., 2009).

AHP treats any hierarchical element as independent while dividing decisions into different tiers, which shape the hierarchical structure (Kheybari et al., 2019). The main form of hierarchical structure is the determination of goals and criteria. The approach provides a means to calculate weights of criteria. In this study, AHP specifically includes means for ranking sustainability criteria and incorporating the result in a GIS environment to identify sustainable sugarcane residue sources. The procedure thus uses a hierarchy of criteria corresponding to factors affecting sustainability of sugarcane residue (see Fig. 2). Such a breakdown provides an opportunity to pursue clarification of the cause and effect between the objectives. (e.g., select the best location of residue source), criteria (e.g., topography), and alternative (e.g., potential location). Once this hierarchical structure has been developed, AHP continues with the weighting of the parameters and the score that calculates the cumulative score for each possible position at each level as well as the overall score. The total score represents the potential location's value, with higher scores indicating more favorable sites.

\subsection{Applying AHP}

In the solution of a multi-criteria problem, the AHP approach provides a method for determining the parameter weights (Akinci et al., 2013) and used to create a consistent collection of relative weights and parameters estimates from an expert (Saaty, 1987). The selection of ideas can be based on the involvement of various people considered experts without a particular number of participants in AHP applications. This study followed simplified steps in applying AHP.

Table 1

Scale of Relative Importance

\begin{tabular}{ll}
\hline Intensity & Definition \\
\hline 1 & Equal Importance \\
3 & Moderate Importance \\
5 & Strong Importance \\
7 & Very Strong Importance \\
9 & Extreme Importance \\
$2,4,6,8$ & Intermediate Values \\
$1 / 3,1 / 5,1 / 7,1 / 9$ & Values of inverse comparison \\
\hline
\end{tabular}


Source: (Saaty, 1987)

Define the Problem and Goal: AHP's first step is to identify the problem and goal setting. In this study the goal is to rank the potential locations of sugarcane residue sources to select the most sustainable area of residue production.

Collect Information Inputs: This stage considers the stakeholders' perception of biomass sustainability regarding sugarcane residues. The group of individuals from the academe, government, and the private sector were the key stakeholders consulted to gather information about the sustainability criteria.

Construct the Hierarchy: Create a hierarchical structure with a goal at the top, attributes or criteria on the second level, and options on the third level. Similarly, it is a decision matrix with criteria with their corresponding alternatives. Each alternative has their own value of criteria associated with them.

Construct Comparison Matrices: A matrix must be created at each level of the hierarchy, with the elements being the relative preference (weight, significance, value, etc.) for each criterion at that level in comparison to all other criteria at that level. The relative importance of various attributes or criteria with respect to the goal is determined by creating a pairwise comparison matrix. A scale of relative importance is used to create the pairwise comparison matrix. Table 1 shows how Saaty's nine-point scale was used in this study to determine the importance or intensity of the experts' judgments.

Depending on the number of sustainability factors, the size of the comparison matrix changed. The three sustainability factors identified in this study were considered using $3 \times 3$ matrices. The weights of criteria subjected to pairwise comparison are used to implement the AHP method. The pairwise comparison matrix is normalized to determine the weights. By dividing the matrix's column elements by the sum of each column, a normalized comparison matrix is obtained. The normalized matrix's row elements are added together, and the total value is divided by the number of row elements.

Compute the Rating: It is necessary to assess the reliability and validity of the decisions made in order to derive reliable weightings for the sustainability factors. The degree of inconsistency in the experts' judgments is determined by a consistency ratio (CR) in AHP, which determines the overall consistency of judgment. According to (Saaty, 1990), CR > 0.1 is unacceptable, necessitating the reconstruction of the pairwise comparison matrix. When the consistency ratio calculated using equation (1) for a judgment is less than 0.1 , it is assumed that the judgments are consistent enough to continue the assessment.

$$
\mathrm{CR}=\mathrm{CI} / \mathrm{RCI}
$$

where, RCI is random consistency index and CI is consistency index, computed using equation (2):

$\mathrm{CI}=\left(\chi_{\max }-\mathrm{n}\right) /(\mathrm{n}-1)$

where, $\chi_{\max }$ is the principal eigenvalue and $\mathrm{n}$ is the number of compared elements. A positive reciprocal matrix was fully consistent when $\chi_{\max }$ was equal to $\mathrm{n}$ (Saaty, 1980).
The more consistent the judgment was, the closer $\lambda_{\max }$ was to $\mathrm{n}$. The consistency index (CI) was developed to calculate the variance from consistency (Alburo et al., 2019).

The value of the random consistency index (RCI) for matrices of order 1-10 obtained with a sample size of 500 is shown in Table 2 (Saaty, 1987). The lower $(<1)$ the CR value, the better the decision makers' decisions, implying that the pair-wise contrast matrix and calculated weights are acceptable. Larger values necessitate the decision maker revising judgment to minimize inconsistencies. Criteria weight is used for further calculation using GIS tools to best determine the residue sustainable location. This study used the open source GIS software tool, QuantumGIS (QGIS) version 3.4.11.

\subsection{Sustainability Analysis}

To identify the factors that affect sustainability of biomass supply and develop a hierarchy of criteria, MCA was employed. Experts from the academe, policy, government, and the private sectors were consulted. The identified factors based on availability of data are topography, cultivation area and accessibility (see Fig. 4, 5 \& 6).

The administrative boundaries map of the Philippines was clipped with the location of Medellin, Cebu using QGIS version 3.4.11. A new field "VALCODE" was added to the clipped shapefile and was given values of 1 for sustainable areas, otherwise 0 . Then the clipped shapefile was converted to raster using Rasterize Tool in QGIS and setting the value field to "VALCODE". This process was done to maps of slope, sugarcane distribution and road network.

The areas with slopes from $0 \%$ to $3 \%$ given its description as level to nearly level land surface as shown in Fig. 3 were the most sustainable areas in order to cultivate sugarcane. Sugarcane cultivation and the utilization of the produced residue for energy generation require the croplands to be big enough in order to supply plenty of crop residues (see Fig. 4). As for accessibility of roads, the primary road was the most valued (see Fig. 5). These primary roads are the ones that directly connect to major cities and provide ease of transportation for the residue collection.

The Weighted Overlay tool is used to solve multicriteria analysis using overlay analysis. Since the input criteria layers would be in various numbering systems with different ranges, each cell for each criterion was reclassified into a standard preference scale such as 0 to 1 , with 1 being the most desirable, to combine them in a single analysis. The stakeholder's preference for the criterion is demonstrated by the assigned preference on the common scale. The preference values are on a scale of 0 to 1 , with 1 being the most sustainable and 0 being the least sustainable. The preference value is not only allocated to each other within each layer, but it also has the same significance across all layers.

The study has three input criteria: slope, sugarcane distribution, and road network. The slopes are reclassified on a scale of 0 to 1, the flatter being less costly; thus, the slopes are the most desirable and the higher values are given. Decreasing values are allocated as the slopes get steeper, with 0 assigned to the steepest slopes. The same reclassification process with the 0 to 1 scale was done for sugarcane distribution. 
Citation: Galang, W.N., Tabañag, I.D., and Loretero, M. (2021) GIS-based Biomass Energy Sustainability Analysis Using Analytical Hierarchy Process: A Case Study in Medellin, Cebu. Int. Journal of Renewable Energy Development, 10(3), 551-561, doi: 10.14710/ijred.2021.33260

Page $\mid 556$

Table 2

Average Random Consistency Index (RCI) at different matrix size

\begin{tabular}{llllllllllll}
$\mathrm{n}$ & 1 & 2 & 3 & 4 & 5 & 6 & 7 & 8 & 9 & 10 \\
\hline $\mathrm{RCI}$ & 0 & 0 & 0.58 & 0.90 & 1.12 & 1.24 & 1.32 & 1.41 & 1.45 & 1.49 \\
\hline
\end{tabular}

Source: (Saaty, 1987)

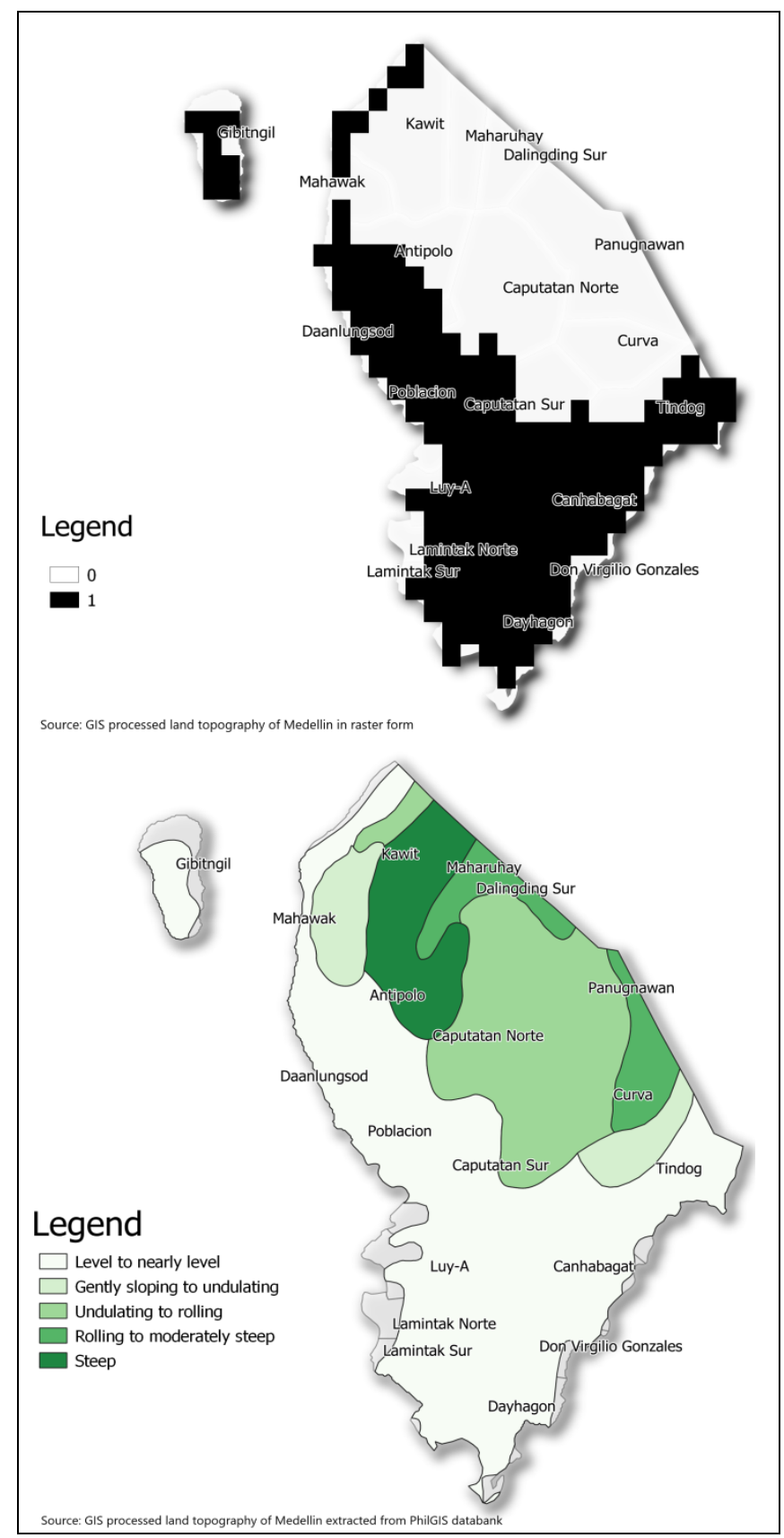

Fig. 3 Slope Map

The larger cultivation area that corresponds to abundant distribution of sugarcane was assigned with the higher values. The same reclassification method is extended to road network criterion. The closer the location is to the road, the less expensive it is to transport residues from collection to energy plants. On the reclassed slope layer, a spot with a sustainability value of 0 would be twice as expensive to use as a slope with a value of 1 . A reclassed slope layer location with sustainability of 0 would have the same cost as a reclassed connectivity to roads layer location with sustainability of 0 .

The weights are multiplied by the input parameters, and the results are accumulated. The criteria weights in the AHP results were used as the multiplier for each of the three raster layers shown in Fig. 4, $5 \& 6$ and the three criteria are added. A Raster Calculator expression in the QGIS environment tool was applied and yielded a sustainability map indicating the potential sites of sustainable residue production of sugarcane.

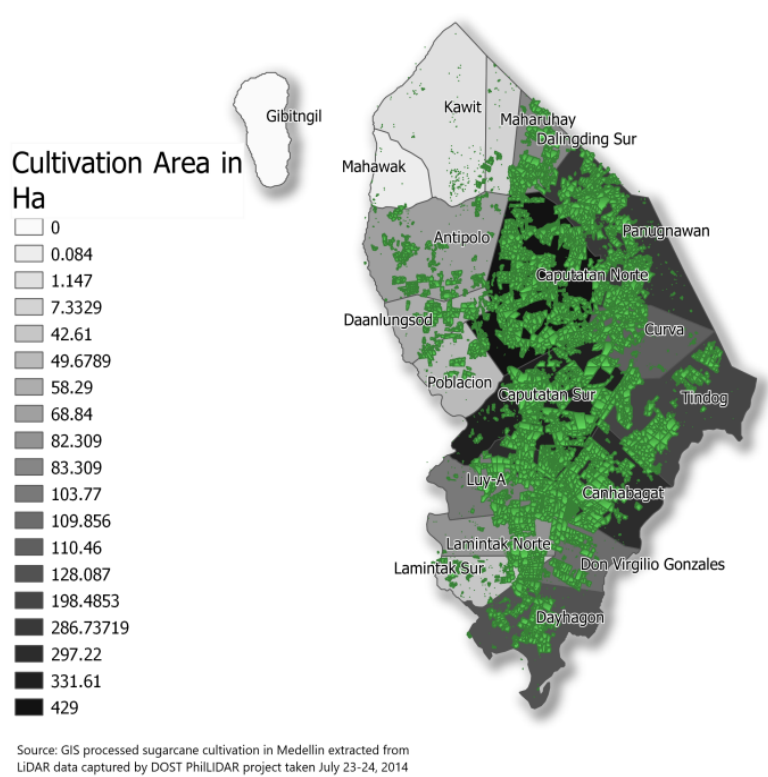

LDAR data captured by DOST Phill DAR project taken wly' 23-24, 2014

Legend

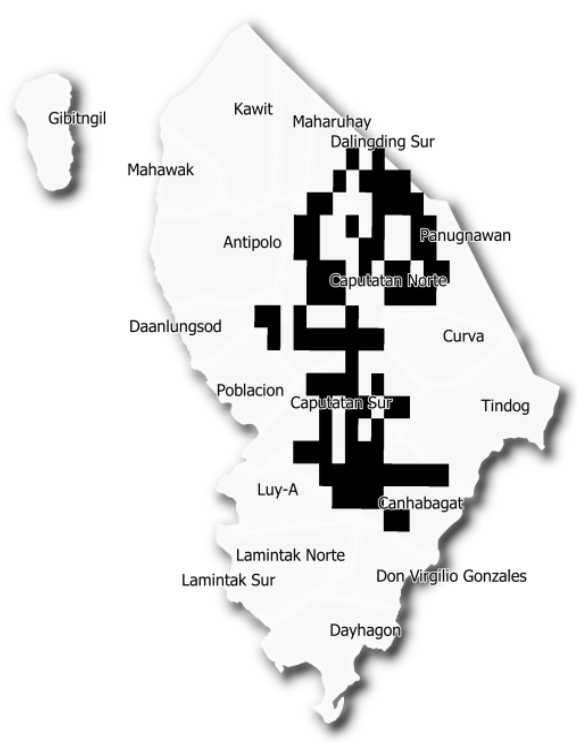

Fig. 4 Sugarcane Distribution Map 


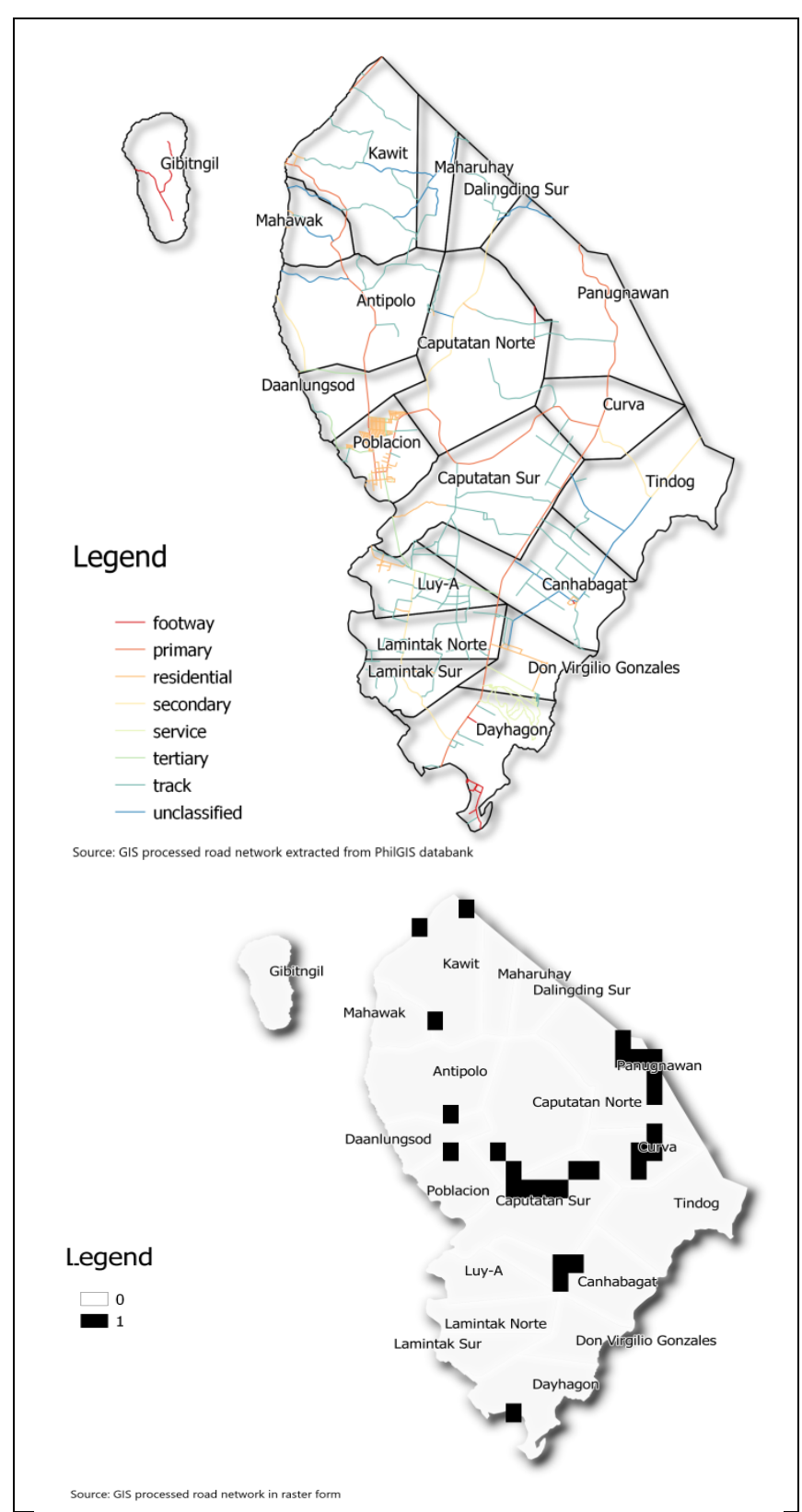

Fig. 5 Road Network Map

\section{Results and Discussion}

Multi criteria analysis revealed the identification of the factors that affect sustainability of biomass supply as shown in the hierarchy of criteria. Experts' judgement was the basis of the identified factors' weight based on availability of data for topography, cultivation area and accessibility. The possibility of cultivating sugarcane is determined by land topography. In Medellin, all the areas with a slope level to nearly level were considered as potential areas for sugarcane cultivation. These areas are identified in which sugarcane is abundantly growing and present. These represent the main economic sectors from which it is possible to obtain process and harvest residues for energy uses. The location must be near the major roads and easily accessible. The primary road in the identified area of study was given the top priority because these are the one that directly connect to major cities Moreover, the croplands must be big enough in order to supply plenty of crop residues. Having the most abundance of agricultural residue guarantees a sufficient energy source for biomass energy generation.

AHP was used to value the chosen parameters using pairwise comparison matrices. In order to evaluate the numerical values determined from the pairwise comparative matrices, an expert decision based on Table 1 is assigned to each criterion. The aim was to measure the matrix consistency ratios (CR), which indicate the arithmetic consistency of the values assigned in each matrix, by calculating the criteria weights of each element in the hierarchies.

The results of the pairwise comparisons in Table 3 display the weights of sustainability measures. The indicator for cultivation area is the highest priority with $72 \%$ of overall weighting followed by topography of $19 \%$. The lowest weight is $8 \%$ for accessibility. Experts found the cultivation area to be a high priority, along with the concern for a sustained supply of residues for energy production. Large sugarcane plantation provides abundant distribution of sugarcane as well as the residue it leaves behind during the harvesting and processing.

By means of a pairwise comparison matrix, the AHP calculates the weight value for each criterion by taking the eigenvector corresponding to the largest eigenvalue of the matrix and then normalizing the total of the components to the unit as shown in Table 4. After obtaining the weight values, it is important to check the matrix's consistency. A consistency ratio, or CR, is used to determine consistency. The consistency ratio (CR) of 0.047 determined using equation (1), revealed accurate judgment in the pairwise comparisons with respect to consistency index (CI) of 0.027 computed using equation (2).

This study considered the Consistency Ratio (CR) of 0.047 that is less than 0.10 to be valid (Saaty, 1990). The assumption is that the pairwise comparison matrix is relatively stable, and that the decision maker can use the parameters weights displayed in Table 3 for further calculations.

\subsection{Sugarcane Residue Production Sustainability}

The weight for each factor was determined using AHP. Based on stakeholders' perception was an assigned relative weight for each factor. The factors were computed and adjusted until $10 \%$ or less of consistency ratio was achieved. These weights were applied to each map layer using Raster Calculator to perform Multi-criteria weighted-overlay analysis in QGIS environment to aggregate the resource maps with respect to the input layers indicated in Table 5. The result is the final sustainability map showing the potential sites for biomass sugarcane residue supply (see Fig. 6). 
Citation: Galang, W.N., Tabañag, I.D., and Loretero, M. (2021) GIS-based Biomass Energy Sustainability Analysis Using Analytical Hierarchy Process: A Case Study in Medellin, Cebu. Int. Journal of Renewable Energy Development, 10(3), 551-561, doi: 10.14710/ijred.2021.33260

Page 1558

Table 3

Pairwise comparison matrix and weights of criteria with AHP

\begin{tabular}{ccccc} 
Criteria & Slope & Land Area & Road Access & Criteria Weight \\
Topography & 1 & 5 & 7 & 3 \\
Cultivation Area & 0.2 & 1 & 1 & 0.193 \\
Accessibility & 0.14 & 0.33 & 0.083 \\
\hline
\end{tabular}

Source: based from experts judgement

Table 4

Normalized pairwise matrix with consistency ration

\begin{tabular}{|c|c|c|c|c|}
\hline Criteria & Slope & Land Area & Road Access & Weighted Sum Value \\
\hline Topography & 0.724 & 0.967 & 0.578 & 2.268 \\
\hline Cultivation Area & 0.145 & 0.193 & 0.248 & 0.586 \\
\hline Accessibility & 0.101 & 0.064 & 0.083 & 0.248 \\
\hline
\end{tabular}

Source: based from experts judgement

Table 5

List of Layers

\begin{tabular}{ll}
\hline Criteria & Corresponding Input Map \\
\hline Topography & Slope Map \\
Cultivation Area & Sugarcane Distribution Map \\
Accessibility & Road network Map \\
\hline
\end{tabular}

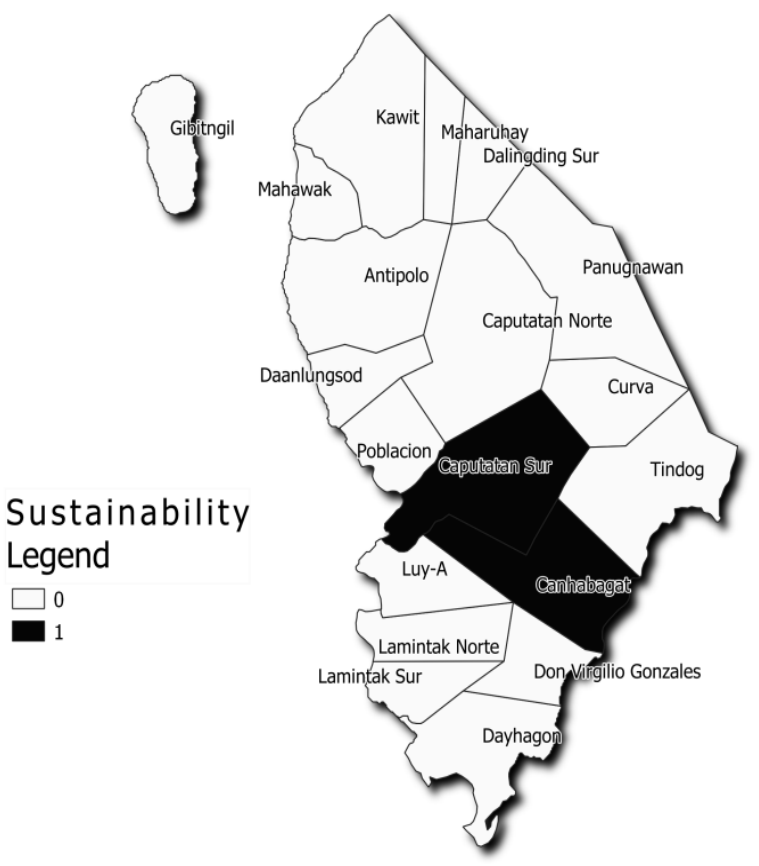

Fig. 6 Sustainability Map

QGIS tool used the following Raster Calculator Expression:

$$
\begin{aligned}
& \text { (0.724* "cultivation_area_layer") } \\
& +(0.193 * \text { "topography_layer") } \\
& +(0.083 * \text { "accesibilty_layer") }
\end{aligned}
$$

The result revealed the location of Caputatan Sur and Canhabagat as the most sustainable areas for sugarcane residue production with respect to topography, cultivation area and road accessibility.

There are nineteen barangay or villages comprising the municipality of Medellin. Except for barangay Gibitngil that was not included in the analysis due to data unavailability up to this date, the eighteen barangays were analyzed for sustainability of sugarcane residue resources. Northeast parts of the study area were characterized by rolling to steep slopes making it challenging to cultivate and harvest sugarcane compared to the rest of the municipality. The interior area of the municipality is linked by primary roads that connect to major economic areas and ideal for transporting goods and services. This is supported by large cultivation areas of sugarcane in mostly interior barangays as the slope favors it with level to nearly level land surface. Most of the large areas of sugarcane cultivation are situated in the interior barangays including Caputatan Norte, Caputatan Sur, Canhabagat and Panugnawan. Large concentrations of sugarcane are distributed among these areas that leave a useful amount of harvest and process residues for energy generation (see Fig. 7 and Fig. 8).

The sustainability map was able to identify two locations, namely, Caputatan Sur and Canhabagat on the basis of land surface, concentration of residues with respect to sugarcane distribution and road accessibility. Although Caputatan Norte and Panugnawan compose $30 \%$ of the cultivation area for Medellin and produced large amounts of sugarcane but the topography were mostly undulating to rolling and accessibility were less linked by primary roads.

\subsection{Effect of Environment}

The Analytical Hierarchy Process (AHP) was used to assess the relative value of the various sustainability factors to sugarcane, as well as the impact of each factor on residue production. Geographic characteristics for abundant sugarcane production and the residue that can be collected are influenced by topography or slope. A slope 
characterized by level to gently sloping is highly suitable for sugarcane cultivation. Undulating to rolling slope is moderately suitable while rolling to moderately steep locations is rated as marginally suitable for cultivation. Slope that is steep is ranked not suitable by the evaluators. Slope orientation was found to be crucial as the influence of slope orientation would have a considerable effect on the amount of solar radiation absorbed by the surface and the vegetation cover (Bennie et al., 2008). The study revealed cultivation area as a major determining factor in residue sustainability. The larger the sugarcane plantation guarantees a more sustainable supply of residue that can be collected during harvest and processing. The result of expert judgement showed a close link between cultivation areas allotted for sugarcane production and the orientation of slope. The road accessibility was least in priority mainly due to the main goal of the study that focused on the concentration of residue production and not on the identification of plant site facilities in which accessibility plays a vital role.

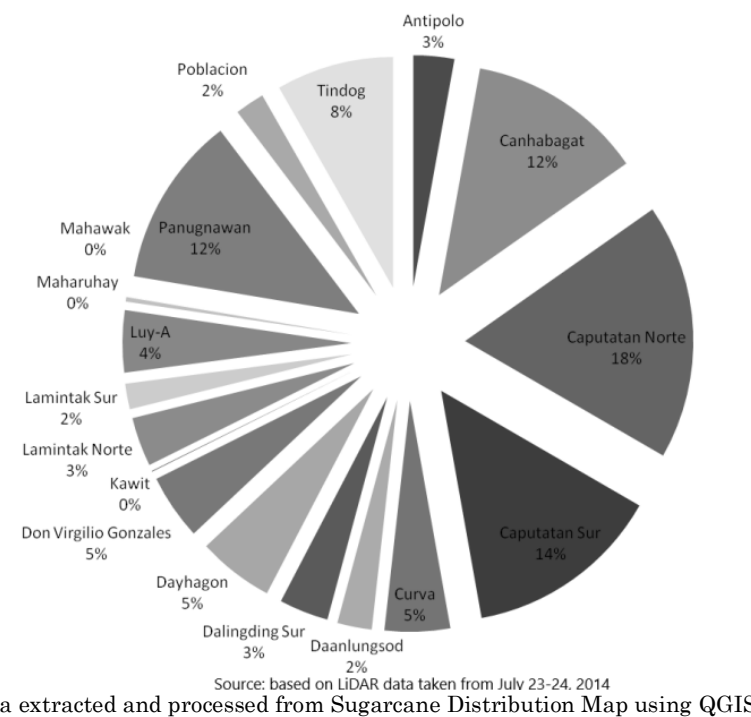

Fig. 7 Barangay Medellin sugarcane cultivated area

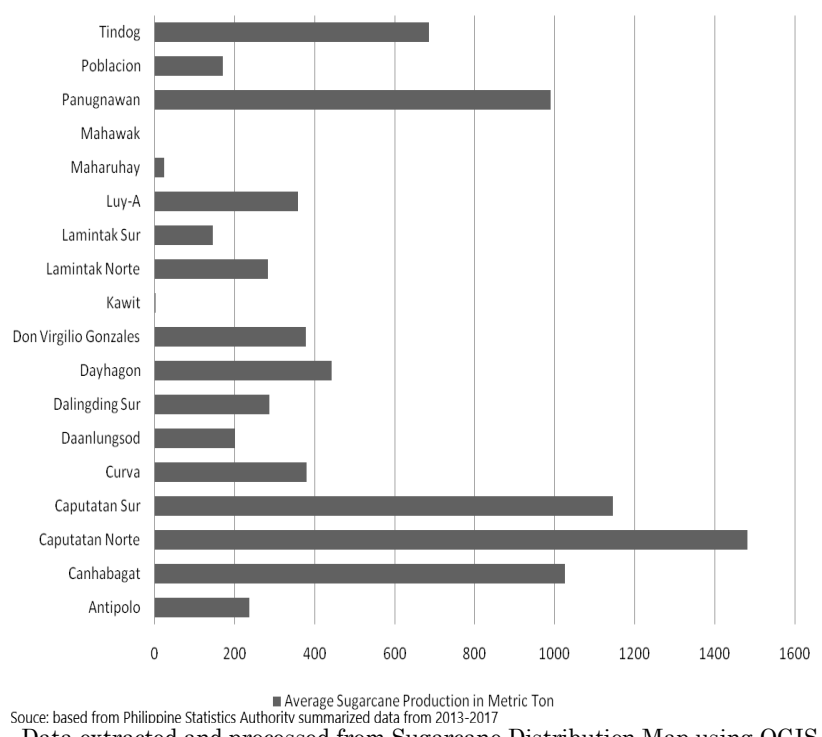

Data extracted and processed from Sugarcane Distribution Map using QGIS
Daticen Fig. 8 Barangay Medellin sugarcane production

\subsection{Effect of Technology}

The significance of sugarcane residue for energy generation is related to fuelwood. Their environmental aspect of production expanded from various local applications to global climate change or from kitchen applications to electricity generation or even large-scale power plants (Kyriakopoulos et al., 2015). Biomass in the form of agricultural crops as well as fuelwood is a renewable energy source that enables sustainable and carbon neutral production and exploitation with respect to its technology applications. Energy produced from fuelwood and agriculture can be used to reduce such greenhouse gas emissions related to energy use by replacing fossil fuel (Kyriakopoulos et al., 2015). Several technologies have been developed to turn biomass into electricity, the most significant of which are gasification, bioethanol, biogas, biodiesel and combustion production technologies (Kheybari et al., 2019). A wide variety of feedstocks from low to high moisture content, including agricultural residues, is used to transform biomass into combustion energy since this form of technology is easy and fully commercialized (Kheybari et al., 2019). This study does not assess the technology but emphasizes the benefit of utilizing indigenous resources for energy generation in replacement for the extensive use of fossil fuel resources.

\subsection{Effect on Local Community}

The sustainable residue production accompanied by steady supply of residue production coming from sugarcane or even fuelwood can lead to the improvement of the local environment because it provides incentives to landowners and farmers and traders to plant under environmentally viable policies (Kyriakopoulos et al., 2015).

The sustainability criteria in this study consider the physical and economic factors to identify potential sites for sugarcane residue production. Additionally, other sustainability metrics, such as greenhouse gas balance, food competition, local energy production, ecology and community well-being involved in the recovery of sugarcane residues, will need to be considered in order to fully assess and provide strategic means of optimizing the available resources. Nonetheless, current work provides a foundation for further exploration of the use of sugarcane residues as a local bioenergy resource.

\section{Conclusion}

AHP is a decision-making methodology involving structured hierarchy of multiple choices, the assessment of the relative value of these parameters, the comparison of alternatives to each criterion and the establishment of an overall alternative ranking. In this study, AHP is particularly useful as it allows for the analysis of data which suits the decisions commonly made by stakeholders. Stakeholders need to prioritize various criteria, such as, physical and economic factors. All of these factors were combined and assessed together that yield to location identification. Through AHP, the judgments, personal values, and preferences of the stakeholders were taken 
into account through explicit weights. This allows them to assess the relative importance of multiple criteria in an intuitive manner.

The combination of AHP and multi-criteria weightedoverlay analysis in a GIS environment provides an overview of the sustainable location for sugarcane residues production in spatial representation. The methodology provided a means to input stakeholders' individual knowledge about identification of factors that affect sustainability of biomass supply, which are, topography (physical factor), cultivation area and accessibility (economic factors). GIS-based with AHP answers the question on which of those factors are relevant, how they should be grouped, and in which levels. In doing so, the information necessary to come up with a sustainable map was generated.

The study was able to identify two sustainable locations for sugarcane residue production using the MCA-GIS based on the set of physical and economic criteria defined, evaluated and weighted in the context of Saaty's analytic hierarchies. The model was applied in the municipality of Medellin, Cebu where sugarcane is mostly abundant. First location is Caputatan Sur, which represents $14 \%$ of the total cultivation area and a 2,712 population as determined by the 2015 Census. Second location is Canhabagat, representing $12 \%$ of the total cultivation area of Medellin and a 2,355 population as determined by the 2015 Census. The assessment model offers a helpful guide for decision-makers in the establishment of a clear means of choosing a potential location for renewable energy supply. The integration of MCDA and GIS approaches can also be used as an effective technique for solving challenges in power planning, such as location identification. This study provides the initial information on the methodology that can be replicated by the local community to support the country's goal in promoting the use of indigenous resources to power the local community.

\section{Acknowledgments}

The authors wish to thank the Philippine GIS Data Clearinghouse for providing a free GIS data for the Philippines. We are also grateful to DOST for the financial support given and University of San Carlos, School of Engineering for the accessibility and use of available facilities.

\section{References}

Akinci, H., Özalp, A. Y., \& Turgut, B. (2013). Agricultural land use suitability analysis using GIS and AHP technique. Computers and Electronics in Agriculture, 97, 71-82. https://doi.org/10.1016/j.compag.2013.07.006

Alburo, J. L. P., Garcia, J. N. M., Sanchez, P. B., \& Cruz, P. C. S. (2019). Application of analytical hierarchy process (AHP) in generating land suitability index (LSI) for sugarcane in central Mindanao, Philippines. Journal of the International Society for Southeast Asian Agricultural Sciences, 25(1), 148158.

Avcıŏglu, A. O., Dayığlu, M. A., \&Türker, U. (2019). Assessment of the energy potential of agricultural biomass residues in Turkey. Renewable Energy, 138, 610-619. https://doi.org/10.1016/j.renene.2019.01.053
Belton, V., Stewart, T. J. (2002). Multiple Criterial Decision Analysis. An Integrated Approach. Kluwer Academic Publishers.

Bennie, J., Huntley, B., Wiltshire, A., Hill, M. O., \& Baxter, R. (2008). Slope, aspect and climate: Spatially explicit and implicit models of topographic microclimate in chalk grassland. Ecological Modelling, 216(1), 47-59. https://doi.org/10.1016/j.ecolmodel.2008.04.010

Boyle, G. (1996). Renewable energy power for a sustainable future. Oxford University Press.

Budak, G., Chen, X., Celik, S., \&Ozturk, B. (2019). A systematic approach for assessment of renewable energy using analytic hierarchy process. Energy, Sustainability and Society, 9(1). https://doi.org/10.1186/s13705-019-0219-y

Cadalin, M. B., Silapan, J. R., Remolador, M. V., \& Ang, M. R. C. O. (2015). Biomass resource assessment on theoretical and available potential of sugarcane using LiDAR-derived agricultural land-cover map in Victorias City, Negros Occidental, Philippines. ACRS 2015 - 36th Asian Conference on Remote Sensing: Fostering Resilient Growth in Asia, Proceedings.

Dincer, I. (2000). Renewable Energy and Sustainable Development: A crucial review. Renew. Sustain.Energy Rev., $4(2), 157-175$.

Ding, G. K. C. (2008). Sustainable construction-The role of environmental assessment tools. Journal of Environmental Management, 86(3), 451-464. https://doi.org/10.1016/j.jenvman.2006.12.025

Electric Power Industry Management Bureau (EPIMB), \& Department of Energy (DOE). (2017). 2016 Philippine Electricity Demand-Supply. 2016 Philippine Electricity Demand-Supply Snapshot, 2, 1-14. https://www.doe.gov.ph/sites/default/files/pdf/electric_power/ power_situationer/2016_power_situation.pdf

FAO. (2017). Crops Processed.

Giri, S., Nejadhashemi, A. P., \&Woznicki, S. A. (2016). Regulators' and stakeholders' perspectives in a framework for bioenergy development. Land Use Policy, 59, 143-153. https://doi.org/10.1016/j.landusepol.2016.08.028

Go, A. W., \&Conag, A. T. (2019). Utilizing sugarcane leaves/straws as source of bioenergy in the Philippines: A case in the Visayas Region. Renewable Energy, 132, 1230-1237. https://doi.org/10.1016/j.renene.2018.09.029

Kamaruzzaman, S. N., Lou, E. C. W., Zainon, N., Mohamed Zaid, N. S., \& Wong, P. F. (2016). Environmental assessment schemes for non-domestic building refurbishment in the Malaysian context. Ecological Indicators, 69(2016), 548-558. https://doi.org/10.1016/j.ecolind.2016.04.031

Kheybari, S., Rezaie, F. M., Naji, S. A., \& Najafi, F. (2019). Evaluation of energy production technologies from biomass using analytical hierarchy process: The case of Iran. Journal ofCleanerProduction, 232,257-265. https://doi.org/10.1016/j.jclepro.2019.05.357

Kurka, T. (2013). Application of the analytic hierarchy process to evaluate the regional sustainability of bioenergy developments.Energy,62,393-402. https://doi.org/10.1016/j.energy.2013.09.053

Kyriakopoulos, G. L., Chalikias, M. S., Kalaitzidou, O., Skordoulis, M., \&Drosos, D. (2015). Environmental viewpoint of fuelwood management. CEUR Workshop Proceedings, $1498,416-425$.

Malczewski, Jacek, Rinner, C. (2015). Multicriteria Decision Analysis in Geographic Information Science. Springer Berlin Heidelberg.

Milbrandt, A., \&Overend, R. P. (2008). Survey of Biomass Resource Assessments and Assessment Capabilities in APEC Economies. Production, November.

Morato, T., Vaezi, M., \& Kumar, A. (2019). Assessment of energy production potential from agricultural residues in Bolivia. Renewable and Sustainable Energy Reviews, 102(November 2018), 14-23. https://doi.org/10.1016/j.rser.2018.11.032

Myllyviita, T., Leskinen, P., Lähtinen, K., Pasanen, K., Sironen, 
S., Kähkönen, T., \&Sikanen, L. (2013). Sustainability assessment of wood-based bioenergy - A methodological framework and a case-study. Biomass and Bioenergy, 59, 293-299. https://doi.org/10.1016/j.biombioe.2013.07.010

Novero, A. U., Pasaporte, M. S., Aurelio, R. M., Madanguit, C. J. G., Tinoy, M. R. M., Luayon, M. S., Oñez, J. P. L., Daquiado, E. G. B., Diez, J. M. A., Ordaneza, J. E., Riños, L. J., Capin, N. C., Pototan, B. L., Tan, H. G., Polinar, M. D. O., Nebres, D. I., \&Nañola, C. L. (2019). The use of light detection and ranging (LiDAR) technology and GIS in the assessment and mapping of bioresources in Davao Region, Mindanao Island, Philippines. Remote Sensing Applications: Society and Environment,13(April2018),1-11. https://doi.org/10.1016/j.rsase.2018.10.011

PSA. (2018). Volume of Production by Region and by Province.

(PSA), P. S. O. (2018). Philippine Statistics Authority Selected Statistics. www.psa.gov.ph

Saaty, R. W. (1987). The analytic hierarchy process-what it is and how it is used. Mathematical Modelling, 9(3-5), 161-176. https://doi.org/10.1016/0270-0255(87)90473-8

Saaty, T. L. (1990). How to make a decision. International Series in Operations Research and Management Science, 175, 1-21. https://doi.org/10.1007/978-1-4614-3597-6_1

Samson, R., Helwig, T., Stohl, D., \&Maio, a De. (2001). Strategies for Enhancing Biomass Energy Utilization in the Philippines Strategies for Enhancing Biomass Energy Utilization in the Philippines. October, October.

Sandoval, J. A., \&Tiburan, C. L. (2019). Identification of potential artificial groundwater recharge sites in Mount Makiling Forest Reserve, Philippines using GIS and Analytical Hierarchy Process. Applied Geography, 105(March2018), 7385. https://doi.org/10.1016/j.apgeog.2019.01.010

Scott, J. A., Ho, W., \&Dey, P. K. (2012). A review of multi-criteria decision-making methods for bioenergy systems. Energy,42(1),146-156. https://doi.org/10.1016/j.energy.2012.03.074

Sevilla, K. H., Remolador, M. V, Saladaga, I. A., Baltazar, B. M., V, L. C., Rosario, M., \& Ang, C. O. (2015a). Estimation of rice hull energy potential using Landsat-derived agricultural maps in Camarines Sur, Philippines. Internaitonal Scientific Journal, 5 .

Sevilla, K., Remolador, M., Baltazar, B., Saladaga, I., Inocencio, L. C., Rosario, M., \& Models, A. M. (2015b). Comparison of MODIS-Based Rice Extent Map and Landsat-Based Rice Classification Map in Determining Biomass Energy Potential of Rice Hull. 9(12), 1163-1166.

Souza, G. M., Victoria, R. L., Joly, C. A., \&Verdade, L. M. (2015). Bioenergy and sustainability: Policy Brief. Scientific Committee on Problems of the Environment - SCOPE, June $2015,4$.

Sugar Regulatory Administration. (2015). Sugarcane roadmap 2020. Board of Investments, 2(3), 1-309.

Sultana, A., \& Kumar, A. (2012). Optimal siting and size of bioenergy facilities using geographic information system. AppliedEnergy,94,192-201.

https://doi.org/10.1016/j.apenergy.2012.01.052

Vera, I., Langlois, L. (2007). Energy indicators for sustainable development.Energy,32(6),875-882. https://doi.org/10.1016/j.energy.2006.08.006

Wong, J. K. W., \& Li, H. (2008). Application of the analytic hierarchy process (AHP) in multi-criteria analysis of the selection of intelligent building systems. Building and Environment,43(1),108-125. https://doi.org/10.1016/j.buildenv.2006.11.019

Xiong Ying, Guang-Ming Zeng, Guiqiu Chen, L. T. (2007). Combining AHP with GIS in Synthetic Evaluation of EcoEnvironment Quality-A Case Study of Hunan Province, China.EcologicalModelling,209(2-4),97-109. https://doi.org/doi.org/10.1016/j.ecolmodel.2007.06.007

Zheng, G., Jing, Y., Huang, H., Zhang, X., \& Gao, Y. (2009). Application of Life Cycle Assessment (LCA) and extenics theory for building energy conservation assessment. Energy, $34(11)$, https://doi.org/10.1016/j.energy.2009.07.035

Zopounidis, C., Pardalos, P. (2010). Handbook of Multicriteria Analysis. Springer-Verlag Berlin Heidelberg. 